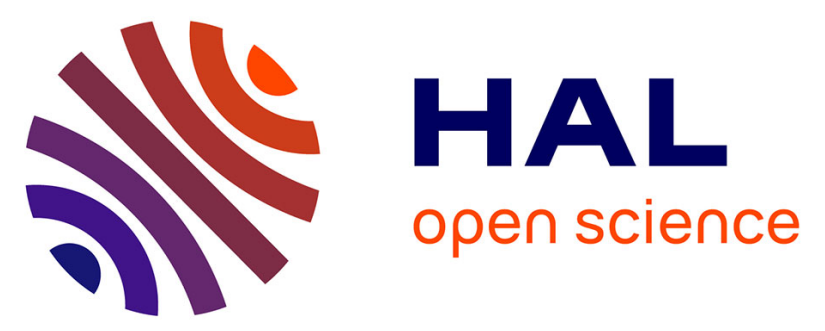

\title{
Speckle and infrared images processing applied to the analysis of the thermomechanical behaviour of a semicrystalline polymer
}

Jean-Michel Muracciole, Bertrand Wattrisse, André Chrysochoos

\section{To cite this version:}

Jean-Michel Muracciole, Bertrand Wattrisse, André Chrysochoos. Speckle and infrared images processing applied to the analysis of the thermomechanical behaviour of a semicrystalline polymer. Michel Frémond; Franco Maceri. Novel Approaches in Civil Engineering, Springer, pp.167-174, 2004, 978-3642-07529-2. 10.1007/978-3-540-45287-4_11. hal-03342694

\author{
HAL Id: hal-03342694 \\ https://hal.science/hal-03342694
}

Submitted on 13 Sep 2021

HAL is a multi-disciplinary open access archive for the deposit and dissemination of scientific research documents, whether they are published or not. The documents may come from teaching and research institutions in France or abroad, or from public or private research centers.
L'archive ouverte pluridisciplinaire HAL, est destinée au dépôt et à la diffusion de documents scientifiques de niveau recherche, publiés ou non, émanant des établissements d'enseignement et de recherche français ou étrangers, des laboratoires publics ou privés. 


\title{
Speckle and infrared images processing applied to the analysis of the thermomechanical behaviour of a semicrystalline polymer
}

\author{
Jean-Michel Muracciole, Bertrand Wattrisse, André \\ Chrysochoos \\ Laboratoire de Mécanique et de Génie Civil - Université Montpellier II \\ Place Eugène Bataillon, C.C. 081, 34095 Montpellier Cedex 5, France
}

\section{Introduction}

The mechanical behaviour of thermoplastics with glassy amorphous regions is characterised by a strong dependence in temperature and strain-rate. It seems thus relevant to take a thermomechanical point of view into account. As these materials may also exhibit both tough dissipation and strong strain localisation, we have decided to use two complementary local techniques to study their response.

Infrared thermography can constitute a highly reliable means to monitor temperature maps during the deformation process of flat samples. The temperature and heat distribution within the specimen obeys the diffusion equation and the heat sources can be locally estimated thanks to the processing of these thermal data.

This determination is a first step, using energy balances, to set up constitutive thermomechanical equations. To achieve such evaluations, the evolution of mechanical data (strain, strain-rate, stress, ...) is also to be detected. During tensile tests, these variables are often supposed to remain homogeneous and their evolution is estimated through rather "global" measurements. In order to analyse the kinematics fields on the same level of space resolution than the thermal ones, we have chosen to develop a digital image correlation technique [Wattrisse et al. 01a].

Results obtained on a semicrystalline thermoplastic polymer (PolyAmide) are presented in this paper. Quasi-static tensile tests, at constant stroke velocity, were performed at room temperature (i.e. below the glass transition temperature) on a MTS hydraulic machine. The conventional stress-strain curve is characterised by a yield, followed by a drop associated with the onset of a neck, which shoulders propagate along the gauge part of the sample.

Two optical sensors with different characteristics (infrared - visible) are set by each side of the machine. We first describe the image processing techniques in the 
infrared spectrum (temperature charts) and for the visible wavelengths (mechanical fields). And, when the deformation process becomes heterogeneous, the analysis of the material behaviour is proceeded by the simultaneous use of these two imaging techniques.

\section{Thermal and calorimetric analysis}

\subsection{Experimental set-up}

The infrared thermography set-up involves a mono-detector camera (Agema 880 SWB, short wave) which records thermal images $(256 \times 180$ pixels $)$ of the flat sample during the loading.

Using the heat equation, the specific heat sources induced by the straining are related to temperature evolutions. For quasi-static tests, assuming an isotropic conduction and neglecting the terms of convection, this relation can be written as [Chrysochoos, 95]:

$\rho C\left(\frac{\partial \theta}{\partial t}+\frac{\theta}{\tau_{t h}}\right)-k \Delta_{2} \theta=w_{c h}^{\prime}$

where $\rho, \mathrm{C}, \tau_{\text {th }}$ and $\mathrm{k}$ stand respectively for the density, the heat capacity, a time constant characterising the lateral heat exchanges, and the heat conductance of the material. The variable $\theta$ represents the deviation from the temperature of the reference state. The specific heat sources $\left(w_{c h}^{\prime}\right)$ can then be determined by applying differential operators on the temperature fields (time derivative: $\partial / \partial \mathrm{t}$ and spatial derivative: $\Delta_{2}=\partial^{2} / \partial x^{2}+\partial^{2} / \partial y^{2}$ where $x$ is the sample loading axis, $y$ the width axis).

\subsection{Infrared data processing}

Before any differentiation, the discrete and noisy thermal data are to be filtered. Several methods can be implemented [Chrysochoos et al, 00a]. Hereafter, a local least square fitting technique has been chosen. The degree of the polynomial is taken equal to 2 , and the regression reflects that, in the neighbourhood of each pixel, heat exchanges by conduction remains locally constant. The Approximation Zone size $(A Z)$ affects evidently the data fitting, and is set to optimise the filtering efficiency. 


\subsection{Validation of the infrared processing}

Computer generated thermal images related to a given heat sources distribution were created in order to validate the infrared data processing. According to our experimental observations, a gaussian white noise $(0.1 \mathrm{~K}$ amplitude), was superimposed to the virtual data. The processing is then applied to these images [Wattrisse et al, 01a]. For $15 \times 15$ square pixels approximation zones, the speed of the computation and the accuracy of the measurement are balanced, as demonstrated in Figure 1.
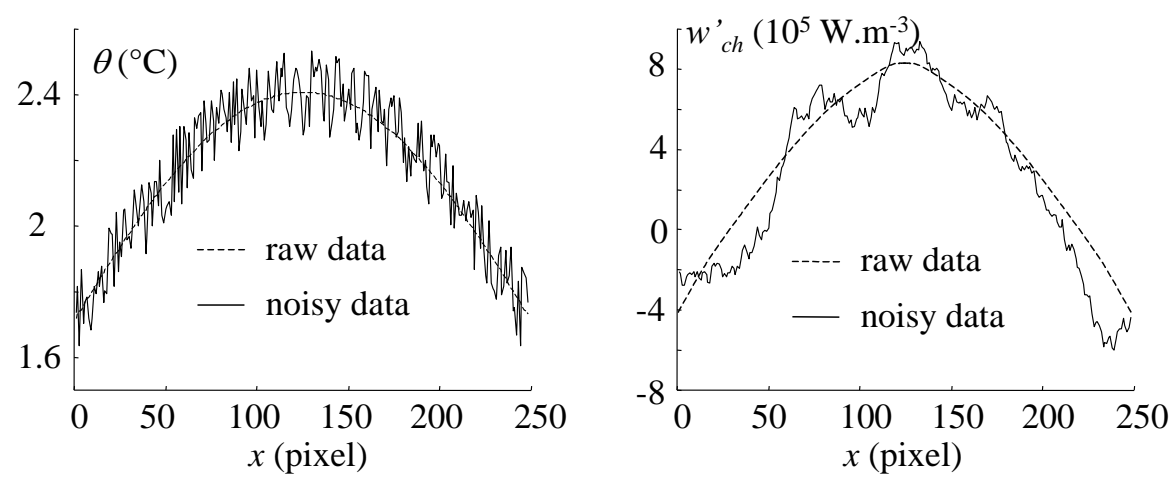

Figure 1: Validation of thermal data processing. Temperature profile $\theta\left(x, 0, t_{0}\right)$ and related heat sources $w_{\mathrm{ch}}^{\prime}\left(x, 0, t_{0}\right)$.

\section{Strain analysis}

\subsection{Experimental set-up}

A C.C.D. camera (Panasonic WV-CP410G) is rooted to the frame of the machine during the test. The image processing is performed afterwards in two steps. The displacement field is first estimated, then the strain and strain-rate fields are deduced by differentiation. 


\subsection{Speckle data processing}

\subsubsection{Displacement field measurement}

The displacement vector of each point is resolved into in-plane and out-ofplane components. The first one is reached by a direct correlation computation. A point, say $M$, is defined by its neighbourhood "optical signature", so-called the Correlation Zone $(C Z)$. The position of $M\left(i_{0}, j_{0}\right)$ in the "reference" image $I_{1}$ is sought inside a Research Zone $(R Z)$ in the "deformed" image $I_{2}$. Its displacement is associated with the couple $(k, l)$ which maximises the intercorrelation function $\varphi$ defined by [Bailey et al, 76]:

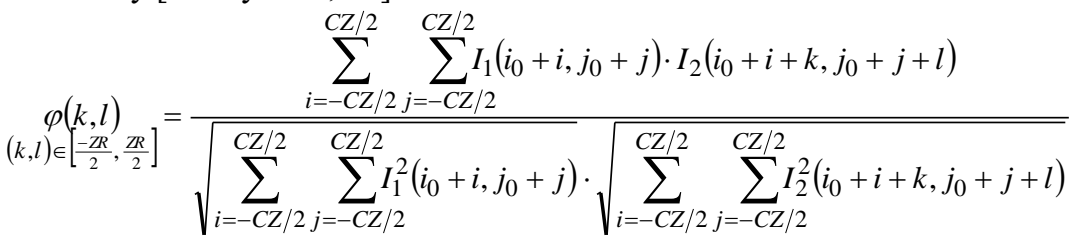

This discrete intercorrelation function leads to a one-pixel resolution in the displacement measurements. In the neighbourhood of $\varphi$ discrete maximum, a polynomial interpolation achieves a sub-pixel resolution [Oulamara et al, 88].

Once the whole displacement vector field has been calculated, the grid is upgraded, and the displacement field between a next couple of images can be determined: the path of each point on the grid is thus calculated step by step.

This approach enables to keep small strain increments between each couple of images, in order to neglect the deformation terms that could be introduced following [Chu et al, 85], [Bruck et al, 89].

\subsubsection{Strain and strain-rate computation}

The differentiation of the displacement field allows to compute a whole range of kinematics fields (speed, acceleration, strain $\varepsilon$, strain-rate $\dot{\varepsilon}, \ldots$ ) [Wattrisse et $a l, 01 \mathrm{a}]$. As with the calorimetric processing, the noisy experimental data are locally filtered using the same kind of polynomial fitting.

\subsection{Validation of the processing}

The algorithms of correlation and differentiation were both tested on several analytic examples based on numerically deformed virtual images, pictured in classical shooting conditions. As illustrated in Figure 2, the use of $20 \times 20$ square pixels Correlation Zones and $25 \times 25$ square pixels Approximation Zones leads to an accurate estimation of strong and weak strain gradients. 


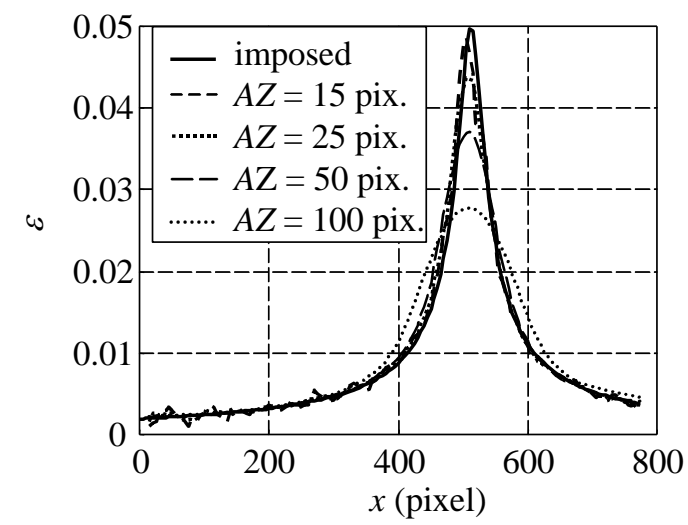

Figure 2: Dependence of the strain measurement with the Approximation Zone dimensions in the case of a heterogeneous strain profile $\varepsilon\left(x, 0, t_{0}\right),(\mathrm{CZ}=20$ square pixels $)$

\section{Coupling of thermal and kinematics measurements}

The results obtained with these two different techniques in very similar conditions [Chrysochoos et al, 00b] - specimen, speed, room temperature, ... motivate their combined use during the same tests as temperature maps and the related material flow are both required to compute the term of convection in the heat equation. Stretching materials with an important heat conduction as metals, at strain-rates about $10^{-2} \mathrm{~s}^{-1}$, this term was found to be negligible [Chrysochoos et al, $00 \mathrm{c}]$. But, in polymers where the heat conduction is poor, important temperature gradients may appear during necking (up to $100 \mathrm{~K} . \mathrm{m}^{-1}$ in PolyAmide 12 for strainrates as low as $10^{-4} \mathrm{~s}^{-1}$ ). Moreover as shown in Figure 3, the shoulder is roughly the only area still straining.

The tests were performed on standard ISO R527 samples with initial gauge length $L_{0}$ of $60 \mathrm{~mm}$ and initial cross-section $S_{0}$ of $40 \mathrm{~mm}^{2}$. In the neck, the term of convection is up to $20 \%$ of the time derivative. The first results presented hereafter illustrate the heterogeneity of the thermomechanical fields during PolyAmide stretching.

\subsection{Local analysis of necking}

As the gradients remain much more acute along the tensile axis $(x)$ than along the sample width $(y)$, only $x$-distributions are taken into account. As shown in Figure 3 , those profiles $-w_{\mathrm{ch}}^{\prime}(x, 0, t)$ and $\dot{\varepsilon}_{x x}(x, 0, t)$ - are piled up in chronological 
order with magnitudes represented using a greyscale: the horizontal axis stands for time (or homogeneous strain) and the vertical for space $(x)$. The engineering stress-strain curve is also plotted onto the map to connect the global mechanical response with the local one. The abscissa then represents the conventional strain $\left(\varepsilon_{\mathrm{C}}=v_{\mathrm{T}} t / L_{0}\right)$, and the ordinate the conventional stress $\left(\sigma_{\mathrm{C}}=F / S_{0}\right.$, where $F$ is the applied load).

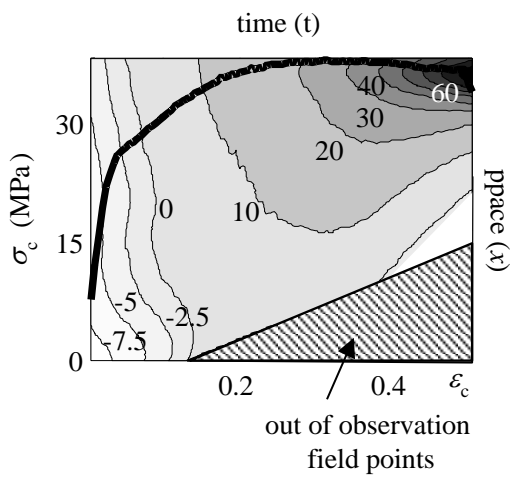

(a)

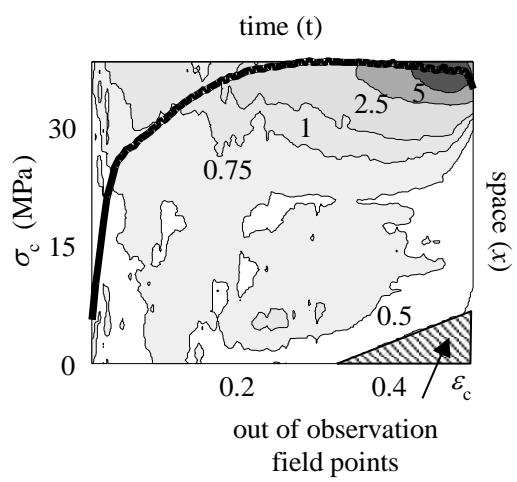

(b)

Figure 3: Tensile test performed on a PA at constant velocity $\left(\mathrm{vT}_{\mathrm{T}}=0.05 \mathrm{~mm} . \mathrm{s}^{-1}\right)$ and at room temperature - (a) distribution of heat sources $\mathrm{w}_{\mathrm{ch}}^{\prime}(\mathrm{x}, 0, \mathrm{t})$ in $10^{3} \mathrm{~W} \cdot \mathrm{m}^{-3}-$ (b) distribution Hencky strain-rate $\dot{\varepsilon}_{\mathrm{xx}}(\mathrm{x}, 0, \mathrm{t})$ in $10^{-3} \mathrm{~s}^{-1}$

At first, the material response is linear. As the stress rises further, it becomes more or less anelastic until yielding occurs. Then, the nominal stress drops somewhat and extension proceeds easily, with the formation of a neck that continuously undergoes growing.

Those three stages can be noticed on the evolution of heat sources (Figure 3.a): they are first negative due to the thermoelastic effect, then they increase as heat is dissipated. And the heat sources concentrate in the necking region when yield occurs. At that stage, strain-rates are also localised (Figure 3.b). The heat sources and the strain-rate are negligible outside the necking zone. The material behaviour can hardly be withdrawn from the engineering curve exhibiting such structural effects: the material local response has to be investigated.

\subsection{Stress analysis}

The main difficulty is here to estimate locally the stress tensor components. A method, based on the exploitation of the strain data and the equilibrium equations is presented in [Wattrisse et al, 01b]. Provided the strain remains homogeneous in each cross-section, and the volume constant, the "true" stress might be written as:

$$
\sigma_{\mathrm{xx}}(\mathrm{x}, \mathrm{t})=\frac{\mathrm{F}(\mathrm{t})}{\mathrm{S}_{0}} \exp \left(\varepsilon_{\mathrm{xx}}(\mathrm{x}, \mathrm{t})\right)
$$


The three stress-strain curves shown in Figure 4 illustrate three different processing of data monitored during the same test. The first one $(G)$, reflects the macroscopic response. The others exhibit the "local" responses of two extensometers: $A$ is located around the point where necking first appears, and $B$ by the point reached by the shoulders of the neck when the test is stopped. Natural strain-rates are also plotted on the same graph.

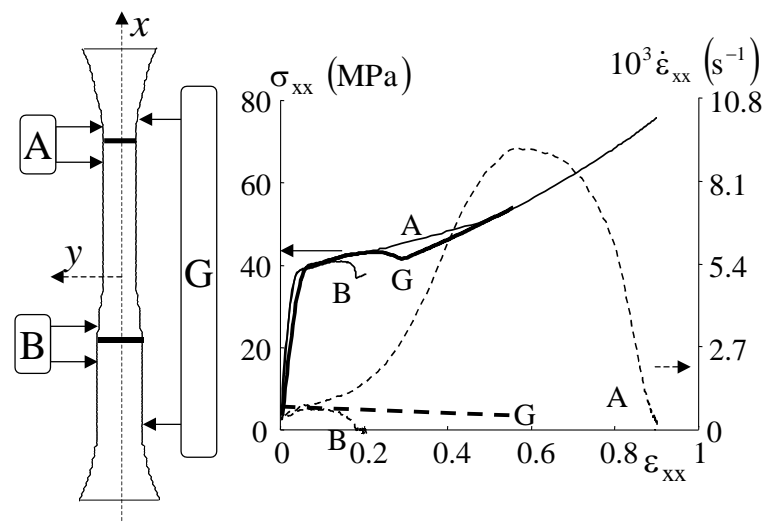

Figure 4: $\sigma_{\mathrm{xx}}-\varepsilon_{\mathrm{xx}}\left(\right.$ full line) and $\dot{\varepsilon}_{\mathrm{xx}}-\varepsilon_{\mathrm{xx}}$ (dotted line) relations for a macroscopic strain $\mathrm{G}$ from 0 to $55 \%$

It is well known that considering the true stress-strain curve in spite of the conventional one increases strain-hardening (see curve $G$ ). This is intensified handling local data (curve $A$ ): the stress increases because the load decrease is always balanced by the section reduction. Between the neck inception and its subsequent propagation the strain-rate increases tenfold. When the neck travels out of the gauge of extensometer $A$, the strain-rate vanishes.

The response of extensometer $B$ is similar until the neck onset. Then the material unloads and it won't strain anymore until the shoulder reaches it. Every other point has a similar behaviour, which is more or less delayed by the neck displacement time. So the whole straining process is concentrated in the vicinity of the neck shoulders.

\section{Conclusions}

This work represents the very first step to proceed energy balances during the deformation of materials undergoing necking. The local material behaviour could be more accurately analysed by the combined use of infrared and speckle techniques, which will be helpful to deduce the nature of the different mechanisms induced by the material deformation. 
In the particular case of PolyAmide, strain-rate and heat sources are concentrated in the neck shoulders. Furthermore, the terms of convection are shown not to remain negligible as the neck propagates, and they are to be taken into account in the heat equation.

Our objective is now to define a local identification method of the material behaviour despite the possible strong heterogeneity of the thermomechanical fields.

\section{References}

[Bailey et al, 76] Bailey, H.H., Blackwell, F.W., Lowery, C.L., Ratkovic, J.A., Image correlation: Part I. Simulation and analysis, United States Air Force Project RAND, R-2057/1-PR, 7-8.

[Bruck et al, 89] Bruck, H.A., Mc Neill, S.R., Sutton, M.A. and Peters, W.H., Digital image correlation using Newton-Raphson method of partial differential correction, J. Exp. Mech., 39, 3, 261-267.

[Chrysochoos, 95] Chrysochoos, A., Analyse du comportement thermomécanique des matériaux par thermographie infrarouge; Photomécanique 95, 203-211, Ed. Eyrolles.

[Chrysochoos et al, 00a] Chrysochoos A., Louche H., An infrared image processing to analyse the calorific effects accompanying strain localisation, Int. J. Eng. Sc., 38,1759-1788.

[Chrysochoos et al, 00b] Chrysochoos, A., Louche, H., Muracciole, J.-M., Saurel, J.-L., Némoz-Gaillard, M., Wattrisse, B., Experimental analysis of localization mechanisms in mild steels by infrared and speckle image processing, IUTAM Symposium «Advanced optical methods and applications in solid mechanics », Poitiers 98, 313-320, Ed. Kluwers.

[Chrysochoos et al, 00c] Chrysochoos, A., Muracciole, J.-M., Wattrisse, B., Experimental analysis of strain and damage localization, Symposium on continuous damage and fracture, Ed. A. Benallal, 41-51.

[Chu et al, 85] Chu, T.C., Ranson, W.F., Sutton, M.A. and Peters, W.H., Application of Digital-Image-Correlation Techniques to Experimental Mechanics, J. Exp. Mech., 25, 232-244.

[Oulamara et al, 88] Oulamara, A., Tribillon, G. and Duvernoy, J., Subpixel speckle displacement measurement using a digital processing technique, J. Mod. Opt., 35.

[Wattrisse et al, 01a] Wattrisse, B., Chrysochoos, A., Muracciole, J.-M., NémozGaillard, M., Analysis of strain localisation during tensile test by digital image correlation, J. Exp. Mech., 41,1,29-38.

[Wattrisse et al, 01b] Wattrisse, B., Chrysochoos, A., Muracciole, J.-M., NémozGaillard, M., Kinematic manifestations of localisation phenomena by image intercorrelation, Eur. J. Mech., A/solids, (to be printed). 